\title{
Solutions for Promoting the Health System and Supplementary Medical Insurance in Iran
}

\author{
Mehdi Riahifar ${ }^{1}$, Seyed Mojtaba Hosseini ${ }^{2}$, Amir Pirouzian ${ }^{1}$, Ali Ayoubian ${ }^{2 *}$ \\ 1 Atiyeh Sazane Hafez, Treatment Supplement Insurance, Tehran, Iran \\ ${ }^{2}$ Department of Health Services Management, College of Management and Social Science, North Tehran Branch, Islamic Azad \\ University, Tehran, Iran
}

Corresponding Author: Ali Ayoubian, PhDc, Department of Health Services Management, Islamic Azad University, North Tehran Branch, Tehran, Iran. E-mail: ayoobian@hotmail.com

Received February 11, 2017; Accepted March 13, 2017; Online Published March 28, 2017

\begin{abstract}
Introduction: Supplemental health insurance is designed to fill the cost gap and service of basic health insurance. The need for supplemental health insurances is inevitable considering the increasing treatment cost on the one hand, and the impossibility of appropriate coverage of all basic services on the other hand. Supplemental health insurances are considered to be optional and provided in a group and, if desired, can be extended to the end of life. The aim of this study was to investigate mechanisms reducing dependence on government with regard to supplemental health insurance and provide high-quality and standard services in the country.

Methods: This research was conducted using a library method, in which the required information was collected through valid domestic and foreign sources and the Internet.

Results: The present study investigated status of treatment insurance and the related problems in Iran. Iran's health status was assessed by investigating the health indicators offered by the World Health Organization. To improve health status and supplemental health insurance, strategies were offered in 20 paragraphs by reviewing the patterns and models presented in the previous studies.

Conclusion: According to the present study, it is recommended to offer various insurance packages considering the age, gender, health status of individuals, geographical status, literacy level, income level, employment status etc.

Keywords: Treatment Insurance; Supplemental Health Insurance; Gross Domestic Product; Health System of Iran

Citation: Riahifar M, Hosseini SM, Pirouzian A, Ayoubian A. Solutions for promoting the health system and supplementary medical insurance in Iran. Int J Med Rev. 2017;4(1):7-16. doi: 10.29252/ijmr-0401.03
\end{abstract}

\section{Introduction}

The growth of knowledge and technology has provided many facilities for discussing health and treatment issues at the societal level. It is not economically feasible to provide the breadth of services to cover the entire population of a country. The costs of these services are increasing due to changes in technology, disease patterns and the demographic structure. ${ }^{1,2}$ Countries have taken steps to develop supplemental medical insurance and increase active involvement of the private sector for the provision of these services. Everyone acknowledges the importance of human health and its effect on production and national income. Protection and safeguarding these national assets are a priority for all governments. In general, insurance is used to replace uncertainty with certainty. Insurance is based on the partnership principle and is one of the most important development factors in countries. Development of insurance is an economic development indicator. Basic health insurance and supplementary medical insurance providers are entrusted with the responsibility of reassuring people about health issues. Basic health insurance, in accordance with Article 29 of the Constitution of the Islamic Republic of Iran, should be provided by the government to every individual from the public income and income obtained from public participation. This insurance includes minimum healthcare services. Failure to provide this level of insurance will threaten community health (regardless of the cost/price ceiling). It is provided in Iran by health insurance organizations, the Social Security Organization and the Armed Forces Medical Services. The need for supplementary health insurance is inevitable considering the increasing treatment costs on the one hand and the impossibility of appropriate coverage of all basic services on the other. Insured persons can use services provided by the public/private sector to fill the service-commitment gap

Copyright (C) 2017 The Author(s). This is an open-access article distributed under the terms of the Creative Commons Attribution License (http://creativecommons.org/licenses/by/4.0), which permits unrestricted use, distribution, and reproduction in any medium, provided the original work is properly cited. 
of the basic health insurance sector through the provision of supplementary medical insurance..$^{2-4}$ When basic health insurance is unable to fully cover essential services and the high costs. Supplementary health insurance is optional and is provided for a group and, if desired, can be extended to the end of life. Studies have shown that people have different expectations about supplementary health insurance. They expect to receive more quantitative and qualitative services from insurance organizations. The government is not able to cover all of these services and there is evident weakness in the health insurance management at the macro level ${ }^{5}$. Various studies have suggested many reasons for the public tendency or lack of participation in supplementary medical insurance services. It is evident that high-income individuals are more likely to use such insurances because of their ability to pay the insurance premiums. 1, 6, 7 Macroeconomic variables such as an increase in national per capita income, decrease in the unemployment rate, price index and per capita damage of $1 \%$, an increase in the demand for insurance by as much as $0.57 \%, 0.27 \%,-0.03 \%$, and $0.75 \%{ }^{8}$. It should be noted that economic variables alone do not cause positive or negative attitudes towards the use of supplementary health insurance and social and cultural indicators also play a significant role in this regard. For example, an increase in the age and level of education has been proven to increase the demand for supplementary medical insurance. ${ }^{6,7,9}$ Nevertheless, increasing age was cited as a factor reducing the demand rate in another study, which could be due to support provided to older people by retirement funds. Another study revealed that risk-averse individuals are more willing to use these services. ${ }^{10}$ Financing health insurance is a major issue in building a culture of using such insurance. Most efforts have aimed at providing patterns and models based on this principle. Emphasis has been placed on the strong presence of institutional shareholders on the board of directors of insurance companies, as these individuals are professional investors who monitor management performance more effectively ${ }^{11}$ according to their level of investment and expertise. The creation of a competitive atmosphere in this area will enable innovation and diversification of the insurance policies issued and the participation of individuals to finance the industry. ${ }^{5,12}$ Note that supplementary medical insurance is never defined as an alternative to health insurance and does not exempt governments from providing comprehensive coverage of basic insurance. However, the current status of supplementary medical insurance in the country reveals problems such as a lack of adequate public knowledge of this section, of necessary and sufficient inclusion of these services and of a clear distinction between basic and supplementary health insurances. ${ }^{3,13}$ Supplementary medical insurance in Iran is administered by the Ministry of Health and Medical Education, the Supreme Council of Public Insurance, Supreme Council of Health and the Central Insurance of
Iran, with the Supreme Council of Health earning the highest rating (78\%). ${ }^{5}$ Regardless of these institutions and organizations, there is insufficient coverage for basic health insurance services (89\%), poor macromanagement of health insurance $(84 \%)$ and the government's inability to cover treatment costs (72\%) have caused individuals to purchase supplementary medical insurance. ${ }^{14}$

Countries have adopted different policies for managing this sector. For example, the United States and Germany have assigned to the private sector the responsibility of providing these services and the government only plays a regulatory and policy-making role. However, the situation is the reverse in Iran where the government has been fully entrusted with the duty of providing the supplementary health insurance. France, a global health pioneer, has also entrusted the private sector with this duty and its only contribution is the allocation of subsidies to prioritized strata. ${ }^{15}$ The supplementary medical insurance industry of Iran is a newly established insurance that is less profitable according to the Central Insurance Statistics of Iran. ${ }^{13}$ Considering the vital importance of identifying deterrent factors and attempting to address them, it is important to identify strengthening factors and promoting the industry to create a cycle with will improve the health of participants and the country's growth and development. Development of solutions and strategic proposals and building on the experience of advanced countries will promote the supplementary medical insurance industry of the country. In this regard, Iranian researchers have proposed different models and solutions. The current review article has attempted to examine the status and problems of health insurance in Iran. It also assesses the national health status by evaluating WHO indicators and the models presented in previous studies are reviewed. Suggestions are offered to improve the status of the health care and supplementary health insurance.

Study Objective

The aim of this study was to investigate the mechanisms that reduce the dependence of supplementary medical insurance on the government and to provide high quality and standard services at the national level.

\section{Methods}

This research was carried out using the library method in which the data required was collected through valid internal and external sources using the Internet.

\section{Results and Discussion}

Status of Supplementary Medical Insurance Industry in Iran

This industry faces many problems in Iran that must be sufficiently understood in order to develop the sector. The following facts indicate that the unfortunate results and reports of recent years in this industry are a growing trend. Supplementary medical insurance accounts for nearly $18 \%$ of the portfolio of the Iranian insurance 
industry and has become a loss-yielding field for insurance companies with a damage coefficient of over $100 \%$ in recent years. Normally, companies are less willing to work in this field. Surveys carried out in in 2016 in research project 47 by the Insurance Research Institute cited two factors as resulting in an increase in the damage coefficient. The first was determination of non-technical premium rates (non-observance of scientific principles in the process of assessing the treatment risks) and predatory pricing in the supplementary medical insurance market. The next was the high rate of health insurance damage for several reasons (aging population, expensive drugs, superior technologies, increase in depressive diseases and psychiatric disorders, etc.) ${ }^{16}$. The Central Bank of the Islamic Republic of Iran reports that the health sector inflation rate has been higher than the general inflation rate in recent years and had increased to $16 \%$ in 2014 . Existing national laws and regulations mean that no private institution can operate in the health sector, including health insurance; thus, insurance companies do not provide insurance services themselves, but merely recruit a mediator between the Iran Insurance Company and individuals. Iran Insurance Company is the main institution responsible for insurance services in the country.

The private sector, which includes supplementary medical insurance, faces major legal problems doing business in the health insurance sector ${ }^{15}$. The transfer of shares of the Alborz, Asia and Dana insurance companies to the private sector occurred in 2008-2009. The public sector exclusively monitors the activities of Iranian insurance companies. Existing private companies who operate under the supervision of the public sector ${ }^{17}$ are: Asia, Alborz, Dana, Parsian, Tose-eh, Razi, Karafarin, Sina, Mellat, Omid, Hafez, Dey, Saman, Iran, Moein, Novin, Pasargadard, Moalem, Mihan, Kowsar, Ma, Motaghabel Kish, Arman, Asmari, Etminan-e Motahed-e Qeshm, Tavon and Sarmad. Table 1 shows the statistics of the insured in the health sector in 2015. As can be seen, the public sector (Iran Insurance) accounted for one-third of the share of insured persons. Based on the negative growth rate in this sector and the increasing growth rate in the nonprivate sector, one would hope for a more vibrant role for this sector and further development of this industry. The number of applicants in this sector is not the most important factor and, according to Figure 1, the share of private health expenditure in recent years has been greater than the share of public health expenditures. Measures should be adopted to manage these costs and expenditures in the private sector. The annual report of Central Insurance of the Islamic Republic of Iran reported that health insurance at $29 \%$ ranked second in the insurance market in 2015 after third-party insurance (40.6\%) in the public sector. It also obtained the highest growth rate of all insurance companies at 33\% and earned a profit by damage coefficient of $90 . \wedge \%$ in that year. The situation was better for the performance of private sector and medical care insurance (20.8\%), which ranked second in the nonpublic insurance market in 2015 after third-party insurance $(35.2 \%)$. This sector recorded the second-highest growth rate $(34.6 \%)$ after shipping insurance (43.8\%) among all non-public sectors. A damage coefficient of $86.1 \%$ in this sector indicates it achieved profitability in $2015{ }^{17}$. These results contradict the trend of past years and could be indicative of positive steps, such as the 2014 health transformation plan, and a sign of hope for a better future in this industry. Figure 2 shows the status of health insurance in the last ten years.

Sigma reports that insurance can be either life or non-life insurance (which includes medical care insurance). A study has shown that life insurance does not have a significant effect on economic growth in the short and long run, but non-life insurance has a significant effect on economic growth in both states ${ }^{18}$. Tables 2 and Table 3 show the status of the insurance industry and non-life insurance according to Sigma in $2015^{19}$. As seen, the Middle East (including Iran) is not desirable, as compared to the global situation, in terms of the share of manufacturing insurance and non-life insurance (including medical care insurance). Although it has a better rank in the non-life insurance category with a share of $2.01 \%$, compared to the $1.18 \%$ share for the entire insurance industry, this is catastrophic as compared with developed regions. The percentage of manufacturing insurance if the gross national product (GNP) for the entire insurance industry (1.88\%) and non-life insurance $(1.42 \%)$ is much lower than in other regions (more than $5 \%$ and $2 \%$ in developed regions, respectively). The situation is little better in terms of per capita insurance share and is not comparable to developed regions at $\$ 152$ and $\$ 115.1$ for the entire insurance industry and non-life insurance, respectively, as shown in Figure 3.

In order to better investigate non-life insurance in the country, it was compared with selected countries (United States, China, Japan, Germany, United Kingdom and France) as well as several countries in the region (Turkey, Saudi Arabia, Pakistan and Egypt) and the result are shown in Table 4. The results indicate that the countries of the region are far behind developed countries in terms of the production rate of the non-life insurance industry, although an upward trend can be seen in this type of insurance for the total insurance share for the countries of the region $(89.5 \%$ for Iran compared to $23.5 \%$ for Japan). This reflects the culture and diversity of insurance in developed countries. Iran can be classified as in the middle, accounting for $0.35 \%$ share of the global market among the countries of the region. However, Iran is far behind developed countries in this regard. Figure 4 compares the per capita premiums among the selected Islamic countries of the region. 
Table 1. Statistics of Persons with Health Insurance in 2015

\begin{tabular}{|lccc|}
\hline $\begin{array}{l}\text { Insurance } \\
\text { Company }\end{array}$ & $\mathbf{2 0 1 5}$ & $\begin{array}{c}\text { Annual } \\
\text { growth } \\
\text { rate }\end{array}$ & $\begin{array}{c}\text { Total } \\
\text { share } \\
(\%)\end{array}$ \\
\hline $\begin{array}{l}\text { Iran } \\
\text { (governmental) }\end{array}$ & $3,852,041$ & $-7.16-$ & 33.13 \\
\hline Asia & $1,301,998$ & 11.30 & 11.20 \\
\hline Alborz & 969,535 & 1.24 & 8.34 \\
\hline Dana & $1,219,727$ & 9.56 & 10.49 \\
\hline Parsian & $1,218,955$ & 13.89 & 10.48 \\
\hline Razi & 178,067 & 22.50 & 1.53 \\
\hline Karafarin & 127,825 & 6 & 1.1 \\
\hline Sina & 627,225 & 134.32 & 5.39 \\
\hline Mellat & 73,255 & 196.52 & 0.63 \\
\hline Omid & 18,036 & 159.10 & 0.16 \\
\hline Hafez & 6,165 & 863.28 & 0.05 \\
\hline Dey & 84,291 & -3.64 & 0.73 \\
\hline Saman & 847,452 & 67.90 & 7.29 \\
\hline Iran Moein & 12,011 & 6.15 & 0.10 \\
\hline Novin & 137,018 & 1.96 & 1.18 \\
\hline Pasargad & 94,633 & -12.76 & 0.81 \\
\hline Moalem & 100,000 & -27.16 & 0.86 \\
\hline Mihan & 127,182 & -40.32 & 1.09 \\
\hline Kowsar & 278,262 & -5.33 & 2.39 \\
\hline Ma & 72,503 & 21.30 & 0.62 \\
\hline Arman & 94,776 & -14.87 & 0.82 \\
\hline Asmari & 70,496 & -19.18 & 0.61 \\
\hline Tavon & 6,838 & -49.54 & 0.06 \\
\hline Sarmad & 108,383 & -10.86 & 0.93 \\
\hline Insurance & $1,626,674$ & 6.57 & 100 \\
\hline industry & & & \\
\hline Source: Central & & & \\
\hline & & & \\
\hline
\end{tabular}

Source: Central Insurance Statistical Yearbook of 2015 for Islamic Republic of Iran ${ }^{17}$

Health Status Survey in Iran

The following WHO indicators were used to assess the health status of the country: health share of GNP index, overall per capita health index (\$US), personal health expenditure as a percentage of total health costs andpersonal share of health costs. Table 5 shows these as a percentage of personal health cost compared to developed countries and Islamic countries of the region between 2000 and 2012. ${ }^{20}$

The results in Table 5 indicate that Iran has gained a high level of growth in this regard, with an increase in the health share of GDP from 4.6 to 6.6 in the 12 -year period, which exceeded the countries of the region; however, it is still far behind the developed countries in this regard. The highest growth rate in Iran's overall health index was observed for the above period ( $\$ 390$ to $\$ 1218$ ), which has also gained a desirable ranking among the countries of the region, although an effective step is needed to approach the status of advanced countries. With regard to two other indicators, the situation of regional countries is worse than in advanced countries.

Saudi Arabia has made significant progress and the outof-pocket health share of people is much lower than in other Islamic countries of the region. Accordingly, people in advanced countries incur less personal health costs because of a greater public infrastructure and facilities (less than 50\%). People's out-of-pocket health expenses are low in France (32.9\%) compared with Iran $(88 \%)$. For the third indicator, there was a $1.2 \%$ increase in public out-of-pocket health cost despite improvement in the first and second indicators in Iran. This means that treatment costs have increased in recent years despite increased production in the health sector. The fourth indicator, people's out-of-pocket health expenditure, in which medical care insurance and supplementary medical insurance play a fundamental role, is high.

Models Proposed to Promote Supplementary Medical Insurance

The following are models provided by Iranian researchers in recent years that promote supplementary medical insurance. Daghighi et al. ${ }^{6}$ used the panel data regression model and the fixed effects model to identify per capita income, per capita health expenditure and the inflation rate as the most important factors influencing people's demand for supplementary medical insurance services. They suggested that public demand will increase with an increase in public awareness through advertising and training, increasing the variety of insurance sales methods (both group and individual methods) and increasing access to service providers. Employers should play a motivating role, insurance coverage should be tailored to customer needs and increased awareness through the media were among their suggestions.

Table 2. Manufacturing Insurance Share in Different Regions of the World in 2015

\begin{tabular}{|c|c|c|c|c|c|}
\hline \multirow[t]{2}{*}{ Countries } & \multicolumn{2}{|c|}{$\begin{array}{c}\text { Percentage in millions of US } \\
\text { dollars }\end{array}$} & \multirow[t]{2}{*}{$\begin{array}{l}\text { Percentage of global } \\
\text { market share }\end{array}$} & \multirow[t]{2}{*}{$\begin{array}{l}\text { GDP percentage in } \\
2015\end{array}$} & \multirow[t]{2}{*}{$\begin{array}{l}\text { Per capita in US dollars } \\
\text { in } 2015\end{array}$} \\
\hline & 2014 & 2015 & & & \\
\hline America & 1610 & 42.6 & 90.34 & 1589385 & 1576073 \\
\hline North America & 9.4006 & 29.7 & 43.31 & 1431239 & 1397751 \\
\hline $\begin{array}{l}\text { Latin America and the } \\
\text { Caribbean }\end{array}$ & 251 & 09.3 & 47.3 & 158146 & 178323 \\
\hline Europe & 4.1634 & 89.6 & 26.32 & 1468878 & 1695091 \\
\hline Western Europe & 4.2580 & 72.7 & 08.31 & 1415185 & 1624812 \\
\hline $\begin{array}{l}\text { Central and Eastern } \\
\text { Europe }\end{array}$ & 6.165 & 92.1 & 18.1 & 53693 & 70279 \\
\hline Asia & 7.311 & 34.5 & 67.29 & 1350974 & 1313874 \\
\hline Advanced markets & 8.3589 & 59.11 & 98.16 & 773059 & 799538 \\
\hline Emerging markets & 140 & 33.3 & 51.11 & 524211 & 462657 \\
\hline $\begin{array}{l}\text { Middle East and Central } \\
\text { Asia }\end{array}$ & 152 & 88.1 & 18.1 & 53704 & 51678 \\
\hline Africa & 7.54 & 9.2 & 41.1 & 64123 & 70116 \\
\hline Oceania & 2065 & 58.5 & 77.1 & 80426 & 99557 \\
\hline World & 2.621 & 23.6 & 100 & 4553785 & 4754710 \\
\hline
\end{tabular}


Table 3. Non-life manufacturing insurance share in different parts of the world in 2015

\begin{tabular}{|c|c|c|c|c|c|}
\hline \multirow[t]{2}{*}{ Countries } & \multicolumn{2}{|c|}{$\begin{array}{c}\text { Percentage in millions of } \\
\text { US dollars }\end{array}$} & \multirow[t]{2}{*}{$\begin{array}{l}\text { Percentage from the global } \\
\text { market share }\end{array}$} & \multirow[t]{2}{*}{$\begin{array}{l}\text { GDP percentage in } \\
2015\end{array}$} & \multirow[t]{2}{*}{$\begin{array}{l}\text { Per capita in US } \\
\text { dollars in } 2015\end{array}$} \\
\hline & 2014 & 2015 & & & \\
\hline United States & 933.3 & 3.72 & 45.61 & 921347 & 915266 \\
\hline North America & 2322 & 4.22 & 41.01 & 829402 & 811771 \\
\hline $\begin{array}{l}\text { Latin America and the } \\
\text { Caribbean }\end{array}$ & 145.9 & 1.8 & 4.55 & 91945 & 103495 \\
\hline Europe & 647.2 & 2.73 & 29.54 & 596763 & 692533 \\
\hline Western Europe & 988.3 & 2.96 & 27.65 & 558561 & 641784 \\
\hline $\begin{array}{l}\text { Central and Eastern } \\
\text { Europe }\end{array}$ & 117.6 & 1.36 & 1.89 & 38202 & 50658 \\
\hline Asia & 102 & 1.74 & 22.10 & 446405 & 427411 \\
\hline Advanced markets & 876.5 & 2.83 & 9.6 & 193885 & 201598 \\
\hline Emerging markets & 56.6 & 1.35 & 10.49 & 211868 & 187388 \\
\hline $\begin{array}{l}\text { Middle East and Central } \\
\text { Asia }\end{array}$ & 115.1 & 1.42 & 2.01 & 40652 & 38426 \\
\hline Africa & 17.4 & 0.95 & 1.01 & 20419 & 22511 \\
\hline Oceania & 899.5 & 2.43 & 1.73 & 35033 & 41398 \\
\hline World & 275.6 & 2.77 & 100 & 2019967 & 2099118 \\
\hline
\end{tabular}

Source: Sigma, World Insurance in 201519

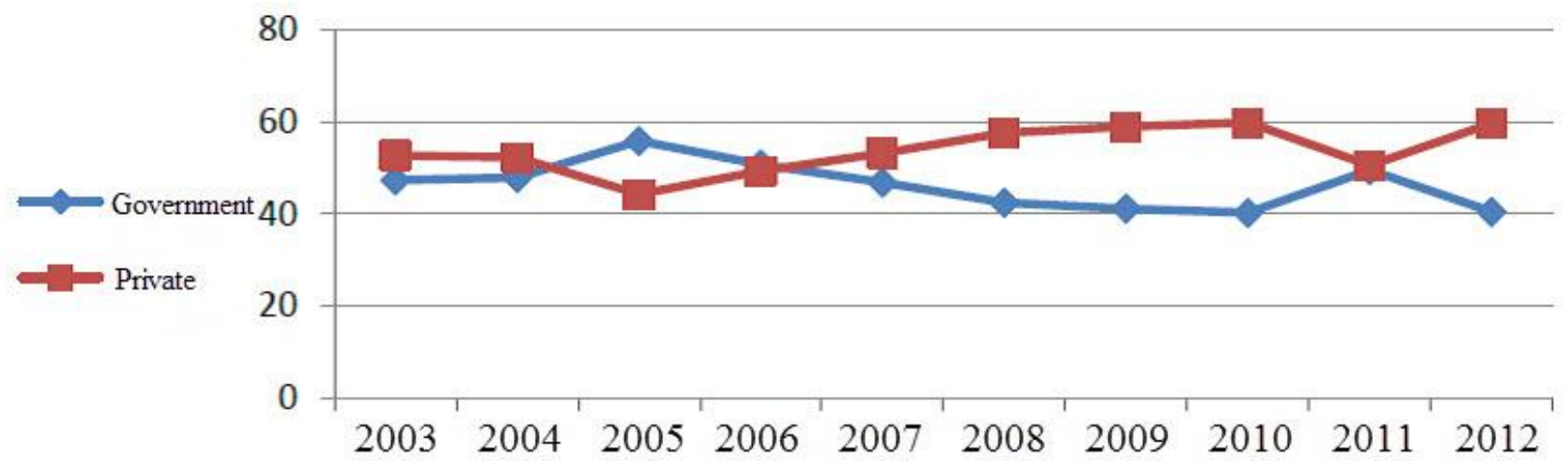

Figure 1. Comparison of Costs and Expenditures of Public and Private Health Sectors. Source: Research Project 47 of Insurance Research Institute $2016^{16}$.

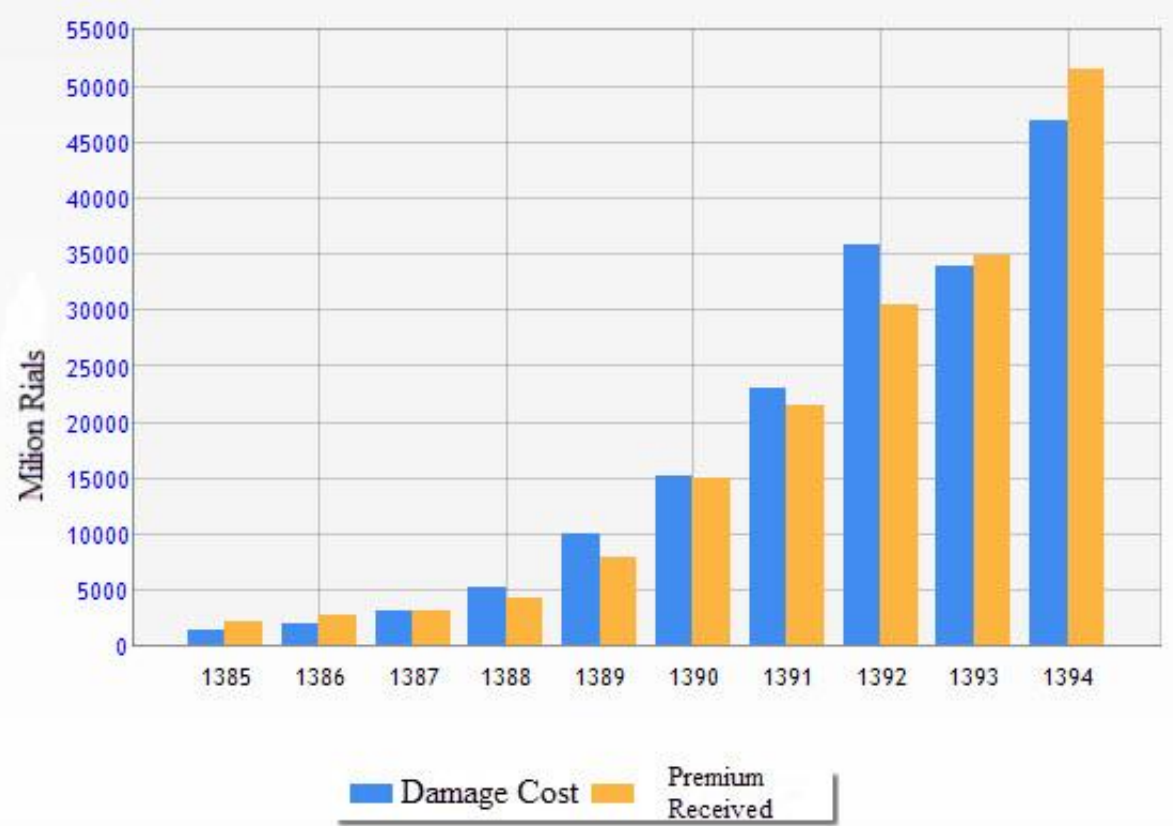

Figure 2. The Premiums and Damage paid by Insurance Companies in the Last Ten Years (Dollars). Source: Central Insurance Statistical Yearbook of 2015 for Islamic Republic of Iran ${ }^{17}$. 


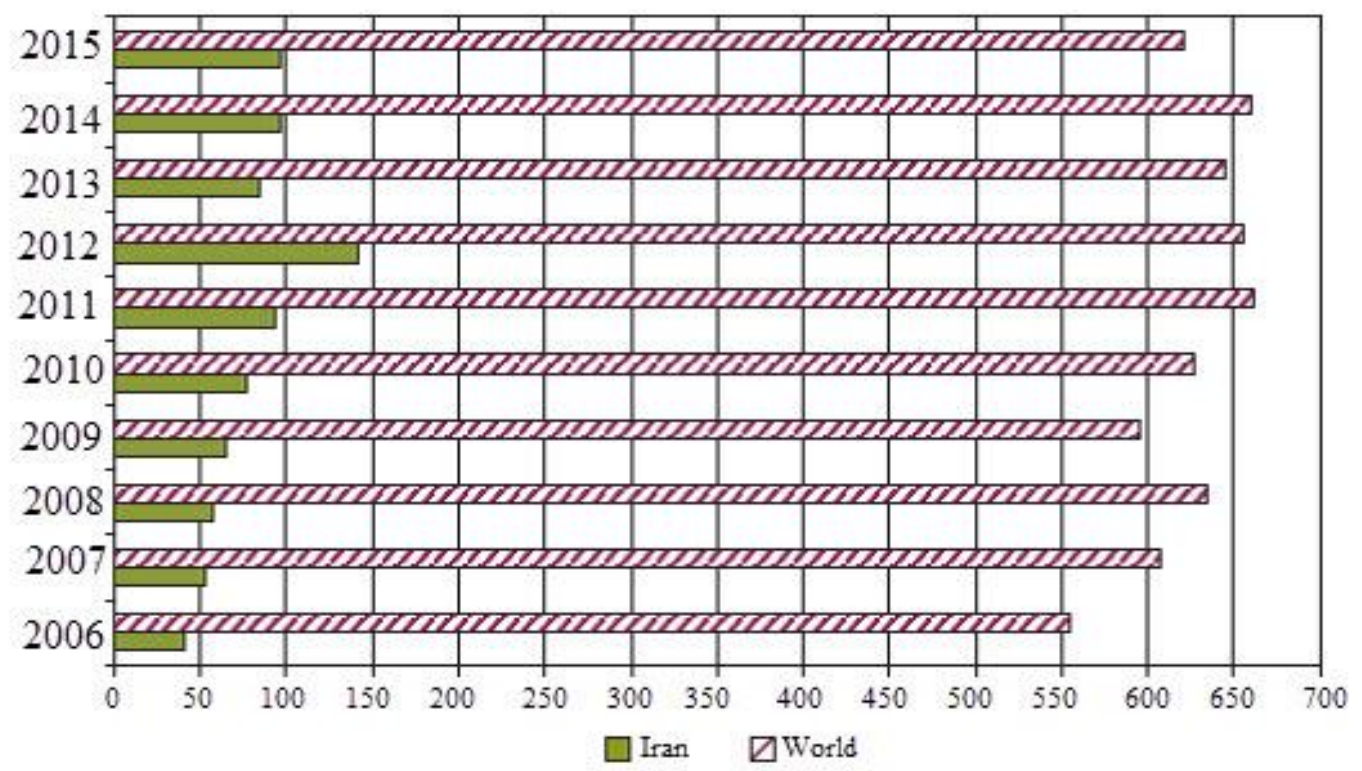

Figure 3. Comparison of Iran's per Capita Premiums with the Global Rate in the Last Ten Years. Source: Central Insurance Statistical Yearbook of 2016 for Islamic Republic of Iran ${ }^{17}$.

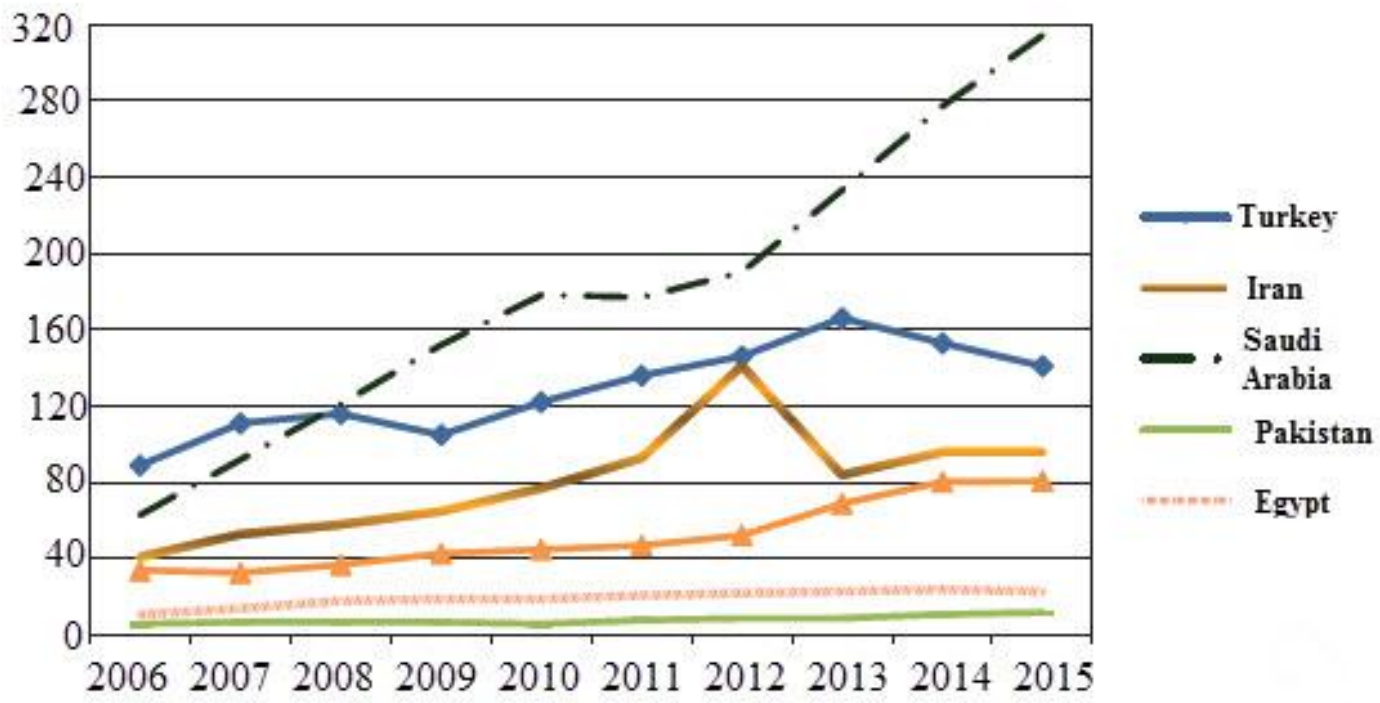

Figure 4. Comparison of Per Capita Premiums among Selected Countries of the Region in the Last Ten Years. Source: Research project 47 of Insurance Research Institute in $2016^{16}$

Table 4. Comparison of Non-life Manufacturing Insurance in Iran and Selected Countries in 2015.

\begin{tabular}{lccccc} 
Ranking & Country & $\begin{array}{c}\text { Sum in million US } \\
\text { Dollars (2015) }\end{array}$ & $\begin{array}{c}\text { Percentage growth } \\
\text { compared to previous year }\end{array}$ & $\begin{array}{c}\text { Percentage of total } \\
\text { insurance share (2015) }\end{array}$ & $\begin{array}{c}\text { Percentage of global } \\
\text { market (2015) }\end{array}$ \\
\hline $\mathbf{1}$ & United & 763766 & 3.3 & 58 & 37.81 \\
& States & & & & 8.7 \\
$\mathbf{2}$ & China & 175737 & 16 & 54.5 & 5.77 \\
$\mathbf{3}$ & Germany & 116538 & -14.7 & 23.5 & 5.24 \\
$\mathbf{4}$ & Japan & 105891 & -5.4 & 33 & 5.23 \\
$\mathbf{5}$ & England & 105685 & -5.8 & 34.9 & 3.98 \\
$\mathbf{5}$ & France & 80402 & -15.3 & 87.8 & 0.48 \\
$\mathbf{2 4}$ & Turkey & 9779 & -3.4 & 97.4 & 0.48 \\
$\mathbf{2 5}$ & Saudi & 9634 & 22.1 & 53.1 & 0.06 \\
& Arabia & & & 33.5 & 0.04 \\
$\mathbf{6 1}$ & Egypt & 1120 & 3.4 & 89.5 & 0.35 \\
\hline $\mathbf{7 5}$ & Pakistan & 731 & 8 & $4 / 44$ & 100 \\
\hline $\mathbf{3 6}$ & Iran & 7052 & 1.6 & -3.8 & \\
\hline-
\end{tabular}

Source: Sigma,World Insurance in $2015^{18}$ 
Table 5. Comparison of National Health Status using WHO Indicators of Developed Countries and Countries of the Region between 2000 and 2012 .

\begin{tabular}{|c|c|c|c|c|c|c|c|c|}
\hline \multirow[t]{2}{*}{ Country } & \multicolumn{2}{|c|}{$\begin{array}{l}\text { Health share index } \\
\text { of GDP }\end{array}$} & \multicolumn{2}{|c|}{$\begin{array}{l}\text { Per capita health } \\
\text { index (US dollar) }\end{array}$} & \multicolumn{2}{|c|}{$\begin{array}{c}\text { Personal health costs as a } \\
\text { percentage of total health costs }\end{array}$} & \multicolumn{2}{|c|}{$\begin{array}{l}\text { The share of people from health costs } \\
\text { as a percentage of personal health costs }\end{array}$} \\
\hline & 2000 & 2012 & 2000 & 2012 & 2000 & 2012 & 2000 & 2012 \\
\hline $\begin{array}{l}\text { United } \\
\text { States }\end{array}$ & 1.13 & 17 & 4818 & 8845 & 57 & 53 & 2.26 & 4.22 \\
\hline Germany & 4.10 & 3.11 & 2682 & 6435 & 5.20 & 3.23 & 9.55 & 56 \\
\hline England & 9.6 & 3.9 & 1833 & 3235 & 9.20 & 16 & 3.53 & 4.56 \\
\hline France & 1.10 & 6.11 & 2556 & 4213 & 6.20 & 6.22 & 4.34 & 9.32 \\
\hline China & 6.4 & 4.5 & 130 & 578 & 7.61 & 44 & 6.95 & 78 \\
\hline Japan & 6.7 & 3.10 & 1992 & 3632 & 2.19 & 9.17 & 1.80 & 2.80 \\
\hline Turkey & 9.4 & 4.5 & 437 & 971 & 1.37 & 2.23 & 6.74 & 3.66 \\
\hline Egypt & 4.5 & 9.4 & 337 & 532 & 5.59 & 61 & 4.97 & 7.97 \\
\hline $\begin{array}{l}\text { Saudi } \\
\text { Arabia }\end{array}$ & 2.4 & 8.3 & 1246 & 1990 & 9.27 & 28 & 1.66 & 3.54 \\
\hline Pakistan & 3 & 8.2 & 81 & 122 & 3.78 & 1.63 & 81 & 79 \\
\hline Iran & 6.4 & 6.6 & 390 & 1218 & 4.58 & 6.59 & 2.96 & 88 \\
\hline
\end{tabular}

Source: WHO World Health Report $2016^{20}$

Abbasi and Taqi-Abadi ${ }^{7}$ showed that there was a positive and significant relationship for per capita income and literacy rates with the demand for supplementary medical insurance from 1991 to 2008. There was no significant relationship between inflation rate, insurance price and unemployment rate with the demand for supplementary medical insurance. They offered several suggestions to increase the demand for supplementary medical insurance. The current and expected inflation rate and national income per capita should be taken into account in the price of insurance policies. The risk of the insured individuals should be scientifically included in the provision of services. In addition to group insurance policies, individual insurance policies should also be submitted. Establishment of a state-funded fund to provide public support for treatment, supervising the expenditures of the insured, the abuse of some insurers, establishment of healthcare centers by insurance organizations using the insurance revenues, acquiring legal personality of insurers and imposing franchises according to age. Wafaei-Najjar et al. ${ }^{5}$ believed that infrastructure and facilities should be provided to improve the current situation. Otherwise, the transfer of these services to the non-public sector will worsen the situation and increase turmoil and confusion, because the conditions for proper growth have not been prepared and the profit rates are subject to imbalances in economic activity. Capital markets do not have the necessary efficiency to participate in the insurance industry and people have a very low level of cultural awareness about insurance. It has been suggested that the issues that should be considered prior to this transfer are determining and guaranteeing supervisory and regulatory bodies as well as the participation of the nonpublic sector. In this regard, it was suggested that extra departmental relations should be developed and unilateralism be avoided by establishing an specialized institution composed of representatives of the Supreme Council of Public Insurance, Ministry of Health, Medical Education, Central Insurance, consumers, service providers, supplementary medical insurance companies and the Ministry of Welfare and Social Security under the supervision of the Supreme Council. The government, as the main overseer, should be also responsible for adopting macro policies in this sector. It should be possible to create a organization that is noncentralized in implementation, but focused on largescale planning. In this regard, the non-public sector will also be able to improve the quality of services and create jobs by complying with the framework, obtaining permission and creating a competitive atmosphere. Considering the determination of the financial sources, it was suggested to design and implement a variety of service packages tailored to customer needs which would increase the people's right to choose the needed services and guarantee cost reimbursement. The use of local independent organizations at specific time points has also been suggested in this study. Researchers of the health insurance organization ${ }^{15}$ have also proposed a model for supplementary medical insurance to raise the level of satisfaction of insured persons and provide more diverse services and better maneuvering power to maintain the dynamism of government insurance organizations as follows: services of supplementary medical insurance, coverage of services and costs outside of the basic insurance coverage provided in accordance with employment status or geographical area, depending on the circumstances and in an optional and competitive manner. The insurance policy issued in this model is for a specified period, which can be extended if the insured is willing, according to the conditions of the previous insurance policy (in compliance with the articles of previous insurance policies) until the end of life in which the precondition to use such services is set in a competitive manner and based on the choice of the insurance institution. The supplementary medical insurance law has been approved by the Islamic Consultative Assembly and government is responsible for issuing the executive regulation. Various supplementary medical insurance providers in the public and private sectors will be formed under the supervision of the Supreme Council of health insurance and are 
required to comply with the guidelines issued by the Supreme Council. Franchises are specified in this model for services covered by insurance companies in a completive manner, to control the consumption pattern, prevent unnecessary demand and pay subsidies for these services for people in need of service providers. The insurance premium is specified based on the following procedures:

A. Different service packages are defined in terms of priority,

B. Separate insurance will be specified for each service package,

C. To earn supplementary insurance premiums, the mechanism of receiving the basic insurance premium must be used,

D. The premium rate is proportional to the payment capacity of most of the insured,

The insurance premium must be paid based on the government subsidies for needy people.

It is necessary to initially provide a clear, unambiguous definition of the key words and terms of supplementary medical insurance and provide appropriate conditions for the formation and activity of private insurance companies with the new legal provisions of the supplementary insurance. All insurance companies should be required to use the codifying the rules and standards of supplementary medical insurance. In order to comply with insured and insurer insurance premiums, standard forms should be designed for insurance contracts and a neutral supervisory body should be appointed to execute these contracts and prosecute possible violations. Service use preconditions should be set in a competitive manner. In this method, the premium is calculated in proportion to the individual and group age and health status in a competitive manner without a limiting premium price ceiling. The premium should also be paid on a joint basis between the insured and insurer. The government should pay a fixed amount as a premium for the needy in the form of subsidies. Prioritized service packages should be identified so that everyone can buy them according to need and financial power. Sheikhan ${ }^{21}$ studied national health using the indices of health share of GNP, health per capita and the fair share of people from health sector expenditures and reported on the adverse health and supplementary medical insurance situation in Iran. He later made the following suggestions by considering both environmental and organizational factors:

- Promotion and advertising of supplement insurance is carried out through policy-making and cooperation of Central Insurance, insurance companies and other relevant organizations and institutions.

- Representatives of the insurance industry, Ministry of Health, Medical Education and the Islamic Republic of Iran Broadcasting should investigate ways to promote and extend the culture of supplementary medical insurance.
- The insurance, financial and investment laws of the insurance industry must be revised with the aim of developing supplementary medical insurance.

- An insurance bank must be formed in partnership with insurance companies to support the sale of insurance policies, facilitate earning of insurance premiums, etc.

- Statistical databases should be designed and established in the supplementary medical insurance industry to help with decisionmaking and executive plans.

- Competent human resources should be trained in specialized fields.

- Electronic systems should be created and developed.

- Specialized insurance companies should be established as a subset of insurance companies.

- A macroeconomic strategy for the insurance industry should be determined and explained for a 20 -year perspective and article 44 of the constitution by designing an operationalization program and determining the contribution of each insurance type, including supplementary health insurance.

- New insurance products, including individual supplementary insurance, should be introduced, because the supplementary insurance is currently offered as group and surplus insurance to applicants and is beyond access to many segments of society.

- The sales network should be re-engineered by evaluating the professional and legal status of the representatives and problems of the sales network and marketers as well as the use of new solutions should be investigated.

- Coherent programs should be designed to reduce public dissatisfaction with the provision of insurance by considering the views of the insured and continuous surveys should be conducted.

- A comprehensive and extensive educational program should be designed to enhance the knowledge and expertise of insurance industry human resources, especially for supplementary medical insurance.

- The authorities should implement methods for earning insurance premiums of the insured individuals using new technologies.

- Books and articles should be published on the achievements of supplementary medical insurance.

- Experts should be sent to other countries for training and practical transfer of experience.

- The following solutions have been proposed to improve the level of supplementary medical 
insurance services in research project 47 of the Insurance Research Institute in 2016:

- The provision of technical rates should be expertized accurately

- Removal of unlimited, non-franchise and lowfranchise contracts from insurance policies

- Supervision of treatment by specialists working in the insurance industry

- Correcting the book on the relative value of services

- $\quad$ Provide companies with a list of insurers with a high damage coefficient to prevent shifting of loss-making insurers between companies

- The main insurance companies should sign a contract with all treatment centers and services providers, whether private or public, in order to reduce loss to business insurance companies

- Health insurance companies should adopt preventive measures to reduce treatment costs, such as periodic check-ups and implementing programs to assess the health status of the insured

- Using and training qualified staff and experts, case studies of documents and contacts with service providers to control and manage frauds

- Providing specific guidelines to prevent the selection of inappropriate risks to the sales network and monitor guideline implementation

- Have standard guidelines for payment of compensatory damages

- Developing clear and up-to-date guidelines and monitoring their implementation accurately by the centers responsible for compensating damages (16)

\section{Suggestions}

1. Based on the foregoing, the following suggestions can be made to improve the performance of supplementary medical insurance in Iran:

2. Approval of new laws that allow private insurance companies to perform the defined activities

3. Grant permits to competent centers and create competitive platforms to reduce out-of-pocket health expenditures and improve the quality of service

4. Support and strengthen the private sector in

\section{References}

1. Raeisi P, Ghaderi $H$, Nosrat Nejad S. [The relationship between macroeconomic variables and the amount of sales of supplementary insurance policies; 1969-282]. Health Manage. 2006;9(24):7-16.

2. Adyani SM, Gol-Alizadeh E. The Need for Complementary Health Insurance in Iran and Suggestions for Its Development. Hosp Pract Res. 2016;1(4):146-. doi: 10.21859/hpr-0104146.

3. Adyani SM, Ahmadi R, Gol-Alizadeh E. The need for supplementary health insurance in Iran. Int J Med Rev. 2017;3(3):472-5 supplementary medical insurance and direct and continuous monitoring by the government of the activities of these sectors

5. Provide diverse insurance packages that take into account age, gender, health status, geographical status, level of education, income level, employment status, etc. 6. Determine the distinction between basic health insurance and supplementary insurance

7. Allocate franchises to prevent unnecessary demand

8 . Use the media to raise public awareness

9. Recruit younger members into the insurance market

10. Monitor hospital and treatment procedures

11. Modify the book of the relative value of services

12. Create statistical databases in the supplementary medical insurance industry

13. Design guidelines for physicians according to the physician-centered health system in Iran

14. Emphasize the central role of Central Insurance of Islamic Republic of Iran as the supervisory and policymaking body of the insurance industry for developing the relevant laws and guidelines

15. Implement screening plans to identify high-risk people and designing special packages for them

16. Provide detailed guidelines to prevent fraud and violations

17. Develop effective human resources through inclusive education and use of the experience of other countries 18. Participation of organizations and institutions such as the Ministry of Education to develop a culture of the use of supplementary medical insurance

19. Perform continuous surveys to identify the causes of dissatisfaction of the insured and eliminate existing deficiencies

20. Individual provision of insurance policies to employers

21. Increase the presence of institutional investors on the board of directors of insurance companies

\section{Authors' Contributions}

All authors contributed equally to this research.

\section{Conflict of Interest Disclosures}

None.

\section{Ethical Approval}

Not applicable.

Funding

None.

4. Zare H. [Introduction to Supplementary Therapies Insurance]. Gen Health Insur Servi. 2003;5(19):20-32.

5. Vafaee Najar A, Karimi I, Sadaghiyani E. [The information system package information package of complementary health insurance services in selected countries and providing a template for Iran]. Health Inf Manage. 2006;3(1):51-62.

6. Daghighi Asli A, Faghih Nasiri M, Aghasi Kermani S. [Estimation of demand function of complementary health insurance in the country's insurance industry]. Ind Insur J. 2009;25(3):119-43. 
7. Abbasi E, Taghi Abadi M. [The effect of economic factors on the demand for supplementary treatment insurance]. Insur J. 2011;26(4):57-80.

8. Lavasani E. [The Relationship between Life Assurance demands and macro Economics Variable in Iran]. Tehran: Islamic Azad University; 2004.

9. Jafari H, Esmaeeli R, Nasiri E, Heidari J, Mohammad Pour M, Mahmoodi G. [The Survey of Mazandaran University of Medical Sciences Satisfaction Survey of Supplementary Therapeutic Services in 2005]. J Mazandaran Univ Med Sci. 2006;17(58):117-24.

10. Nosratnejad S, Purreza A, Moieni M, Heydari H. Factors Affecting the demand for private health insurance in Tehran. J Hosp. 2014;13(2):37-44.

11. Shororzi M, Khalili M, Soleimani H, Forootan O. [Relationship between corporate governance and company performance based on fuzzy regression]. Financ Account Audit Res. 2015;7(25):125-39.

12. Saffari A, Tourkestani M, Moradi P, Golshahi B. [The Effect of Competitive Forces on the Performance of Private Insurance Companies in Iran: The Role of Composite Strategies]. Insur J. 2014;29(2):211-34.

13. Mahmoodi V, Shahhosseini M. [Compilation of the developmental pattern of supplementary insurance of group therapyl. Strat Manage Stud. 2005:5(19):145-76.

14. Vafaee Najar A, Karimi I, Seyed Nozadi M. [Comparative study of the structure and content of complementary health insurance in selected countries and presenting a model for Iran]. Health Manage. 2006;10(28):57-64.

15. Eslami M. [A review of the structure of complementary health insurance in selected countries and Iran]. Insur J. 2004;20(4):197-214.

16. Ashkahs G. [Damage Management Solutions of Supplementary health insurance]. Insur J. 2016;29(3):13240.

17. Iran ClotIRo. [Statistical Yearbook 1394 Insurance Industry] Iran: Central Insurance of the Islamic Republic of Iran; 2014

18. Arena M. Does Insurance Market Activity Promote Economic Growth? A Cross-Country Study for Industrialized and Developing Countries. J Risk Insur. 2008;75(4):921-46. doi: 10.1111/j.1539-6975.2008.00291.x.

19. Swiss-Re S. World insurance in 2015: Steady growth amid regional disparities. Sigma. 2016(3).

20. Organization WH. World health statistics 2016: monitoring health for the SDGs sustainable development goals: World Health Organization; 2016

21. Sheikhan N. [Complementary health insurance in Iran]. J Soc welf. 2013;13(48):247-70. 